\title{
Providers' knowledge of genetics: A survey of 5915 individuals and families with genetic conditions
}

Erin K. Harvey, ScM, CGC $C^{1}$, Chana E. Fogel, MGC ${ }^{2}$, Mark Peyrot, PhD ${ }^{3}$, Kurt D. Christensen, MPH ${ }^{4}$, Sharon F. Terry, $M A^{4}$, and Joseph D. McInerney, $M A, M S^{1}$

\begin{abstract}
Purpose: Individuals affected by genetic conditions are increasingly likely to seek information about inheritance and risk factors from their primary care physicians rather than a geneticist, but several studies suggest that few health care providers are capable of fulfilling that role or are comfortable doing so. Acknowledging that the adoption of new genetics knowledge and technologies is often patient-driven, we asked affected individuals and family members about their experiences in encounters with a variety of nongenetics-trained health care providers. Methods: Staff at the National Coalition for Health Professional Education in Genetics, the Genetic Alliance, and a University of Maryland graduate student in genetic counseling drafted a web-based survey. We recruited study participants from the Genetic Alliance, and a total of 5915 respondents completed the questionnaire between December 2004 and August 2005. Results: Overall, $64 \%$ of respondents reported receiving no genetics education materials from the provider type named most important in the management of the condition in the family. We present knowledge ratings for various provider types and themes emerging from written descriptions of positive and disappointing experiences. Conclusion: We discuss the implications of these and other results for continuing genetics education and for clinical practice. Genet Med 2007:9(5):259-267.
\end{abstract}

Key Words: genetics education, providers' knowledge, advocacy, patients, families

Genetics now has established itself in the United States and in other countries not only as a specialty of medicine but also as a thread throughout all of health care. ${ }^{1,2}$ Individuals affected by genetic conditions are therefore increasingly likely to seek information about inheritance and risk factors from their primary care physicians rather than a geneticist, ${ }^{3}$ but several studies suggest that few health care providers can fulfill that role or are comfortable doing so. ${ }^{4-9}$

There is a concerted impetus from government agencies and scientific groups to educate future practitioners about genetics and to incorporate more genetics into the general practice of health care. ${ }^{10-12}$ Professional societies, advocacy organizations, and government agencies have drafted genetics competencies (see Core Competencies in Genetics Essential for All Health-Care Professionals at www.nchpeg.org), curricular recommendations for training programs, and policy statements for specific disorders, and have launched public campaigns to convey the value of ge-

\footnotetext{
From the ${ }^{1}$ National Coalition for Health Professional Education in Genetics, Lutherville, Maryland; ${ }^{2}$ University of Maryland, College Park Maryland, now at Gallaudet University, Washington, DC; ${ }^{3}$ Loyola College and Johns Hopkins University School of Medicine, Baltimore, Maryland; and ${ }^{4}$ Genetic Alliance, Washington, DC.

Erin K. Harvey, National Coalition for Health Professional Education in Genetics, 2360 W. Joppa Rd., Suite 320,Lutherville, MD 21093.E-mail: ekharvey@comcast.net

The authors declare no conflict of interest.

Submitted for publication November 8, 2006.

Accepted for publication February 20, 2007.

DOI: 10.1097/GIM.0b013e31805002f2
}

netic family history information (see the Surgeon General's Family History initiative at www. hhs. gov/familyhistory/).

Historically, research involving genetic conditions has had a clinical focus and has been conducted by a small subset of the medical community. As our knowledge of genetic contributions to rare and common conditions grows, however, the base of "genetics consumers" is growing and becoming more prominent in health care, providing opportunities for larger and more varied types of investigations. In addition, disease-specific advocacy organizations have robust networks supported by electronic communications, and therefore even rare diseases have accessible representatives. We set out to investigate what individuals and families with genetic conditions experience firsthand in encounters with their providers. Key questions guiding this analysis include:

1. How do respondents rank their health care providers' knowledge of the genetics of the condition in the family?

2. Do people who rate their own knowledge as good or excellent assess their providers' knowledge differently from those who rate their own knowledge as fair or poor?

3. Is consultation with a genetics-trained provider associated with higher self-assessed knowledge scores than is the absence of such consultation?

4. What factors contribute to positive and disappointing experiences with knowledgeable and uninformed providers, respectively?

5. If not from their health care providers, where do respondents find educational information about the genetics of a condition in themselves or family members? 
6. Does the source of disease-related information affect respondents' self-assessed level of knowledge?

\section{MATERIALS AND METHODS}

\section{Study sample}

We recruited study participants from organizations that are members of Genetic Alliance (GA), an international coalition of more than 600 advocacy organizations representing more than 14 million members and more than 1000 genetic conditions. GA invited the leader(s) of each member organization to disseminate the survey instrument to his or her organization through a blast e-mail that included the survey's internet address. We collected no personal identifiers, and all participation was voluntary. This study was reviewed and accepted (number $\mathrm{H}-26237$ ) by the Institutional Review Board for $\mathrm{Hu}$ man Subjects Research at the University of Maryland, Baltimore.

\section{Survey instrument}

The survey asked participants to do the following:

1. share medical-demographic information such as diagnosis, number of affected family members, time since diagnosis, types of providers consulted, and membership in specific advocacy organizations;

2. rank their genetics knowledge of the condition, as well as the genetics knowledge and specific clinical skills for the provider type named "most important" in the management of their condition;

3. identify the most common sources of genetics education information; and

4. write anecdotes about positive and negative experiences with knowledgeable and uninformed providers, respectively.

The survey was accessible online; a back-end Excel database (Microsoft Corp, Redmond, WA) stored electronic submissions. Data collection continued from December 2004 to the end of August 2005 and is the basis for the final study sample used for this analysis.

\section{Data analysis}

We assigned thematic codes to qualitative, written responses and attained greater than $90 \%$ interrater reliability. We analyzed quantitative data from the final data set using the Statistical Package for the Social Sciences 13.0 (SPSS Inc., Chicago, IL) for Windows XP. We calculated parametric and nonparametric tests (analysis of variance, Kruskal-Wallis chi-square, Wilcoxon, ordinal logistic regression) in addition to basic descriptive statistics to answer the research questions posed here. Responses of "poor," "average," "good," and "excellent" were assigned numeric values 1 through 4 to facilitate presentation of results in terms of mean scores. To assess the independent association of an outcome with multiple measures, we used multivariate tests (analysis of variance, ordinal logistic regression); this allowed us to see whether each factor made a con- tribution to the outcome over and above the other factors in the model. When a parametric technique was used to obtain estimates of the size of independent associations for singleitem outcomes, the significance of relationships was obtained by ordinal logistic regression.

\section{RESULTS}

We received 5915 completed surveys from members of 309 unique advocacy organizations. Some $78 \%$ of respondents reported being a member of a formal advocacy organization; $22 \%$ were not, but may have been on a group mailing list or heard about the survey from a friend or family member. We cannot estimate accurately the total number of individuals made aware of the online survey, but the magnitude of the response indicates that it was circulated extensively.

Table 1 shows the 25 most commonly represented conditions among the 5915 respondents, provides the generally accepted incidence and/or prevalence, and lists known modes of inheritance for each condition. It is apparent that the prevalence of a condition does not correlate with the number of responses, which might instead reflect other factors, including the morbidity of the condition, the encouragement of the advocacy group's leadership, and the group's communication channels.

Half of respondents (50.1\%) reported that they did not have the genetic condition identified in the survey. The remaining respondents were divided almost equally between those who are the only one in their family with the condition $(23.0 \%)$ and those who also had a family member with the condition (26.9\%). More than half of the respondents (54.7\%) reported having children with the condition, followed by parents (17.8\%), siblings (14.4\%), and spouses (4.1\%). The majority of respondents also reported having received a diagnosis within 5 years of completing the survey and consulting an average of six different provider types (excluding genetics professionals).

\section{If not from their health care providers, where do patients find educational information about the genetics of a condition in themselves or family members?}

From the total of 5915 responses, 3769 study participants (64\%) reported receiving no genetics-education materials from their providers. Respondents did, however, seek out genetics-related information from the sources detailed in Fig. 1.

\section{Does the source of disease information affect respondents' self-assessed level of knowledge?}

We used multivariate analysis to determine whether the sources in Fig. 1 had independent effects (i.e., effects net of one another) on the assessment of genetics knowledge scores. The sizes of these effects were obtained by comparing estimated mean knowledge scores for those who did versus those who did not report using each source, controlling for the absence/presence of the other sources. With the exception of websites, use of each source of information was significantly $(P<.001)$ associated with an independent increase in self-assessed knowledge 
Table 1

Conditions represented among $53 \%$ of respondents

\begin{tabular}{|c|c|c|c|}
\hline Condition & $\begin{array}{l}\text { No. of } \\
\text { respondents }\end{array}$ & $\begin{array}{c}\text { Incidence }(\mathrm{I}) \text { and/or } \\
\text { population prevalence }(\mathrm{P})\end{array}$ & Inheritance \\
\hline \multirow[t]{2}{*}{ Marfan syndrome } & 465 & 1 in $5,000(\mathrm{P})$ & $\mathrm{AD}$ \\
\hline & & www.marfan.org & \\
\hline \multirow[t]{2}{*}{ Pseudoxanthoma Elasticum (PXE) } & 260 & 1 in $25,000-100,000$ (I) & $\mathrm{AR}$ \\
\hline & & www.pxe.org & \\
\hline \multirow[t]{2}{*}{ Alpha-1-Antitrypsin deficiency } & 243 & 1 in $2,500(\mathrm{P})$ & AR or \\
\hline & & www.alphaone.org & AutoCoDom \\
\hline \multirow[t]{3}{*}{ Tuberous Sclerosis } & 205 & 1 in 6,000 live births (I) & $\mathrm{AD}$ \\
\hline & & 50,000 U.S. (P) & \\
\hline & & www.tsalliance.org & \\
\hline \multirow[t]{2}{*}{ Albinism } & 148 & 1 in 17,000 U.S. (P) & $\mathrm{AR}$ \\
\hline & & www.albinism.org & $\mathrm{XL}$ \\
\hline \multirow[t]{2}{*}{ Spinal Muscular Atrophy (SMA) } & 148 & 1 in 6,000 U.S. (I) & $\mathrm{AR}$ \\
\hline & & www.fsma.org & \\
\hline \multirow[t]{2}{*}{ Long QT syndrome } & 147 & 1 in $3000-5000(P)$ & $\mathrm{AR}$ \\
\hline & & www.emedicine.com & $\mathrm{AD}$ \\
\hline \multirow[t]{2}{*}{ 47, XXY Kleinfelter syndrome } & 140 & 1 in $500-1,000$ male births (I) & Sporadicl \\
\hline & & www.genetic.org/ks/ & Chromosomal \\
\hline \multirow[t]{2}{*}{ Hemorrhagic Telangiectasia } & 138 & 1 in $5,000-10,000(\mathrm{P})$ & $\mathrm{AD}$ \\
\hline & & ghr.nlm.nih.gov & \\
\hline \multirow[t]{2}{*}{ BRCA ( 1 and 2$)$} & 122 & 1 to 2 per $1,000(\mathrm{P})$ & $\mathrm{AD}$ \\
\hline & & www.genetests.org & \\
\hline \multirow[t]{3}{*}{ Fragile X syndrome } & 105 & males: 1 in $4,000(\mathrm{P})$ & Trinucleotide \\
\hline & & females: 1 in 8,000 (P) & Repeat \\
\hline & & www.marchofdimes.com & Expansion \\
\hline \multirow[t]{2}{*}{ Celiac disease/Celiac sprue } & 104 & 1 in 133 U.S. (P) & Complex $^{a}$ \\
\hline & & www.csaceliacs.org & \\
\hline \multirow[t]{2}{*}{ Osteogenesis imperfecta } & 92 & $6-7$ in $100,000(P)$ & Most AD \\
\hline & & www.genetests.com & \\
\hline \multirow[t]{2}{*}{ Psoriasis } & 92 & 2 in 100 U.S. (P) & Complex $^{a}$ \\
\hline & & www.psoriasis.org & \\
\hline \multirow[t]{2}{*}{ Down syndrome } & 90 & 1 in 800 (I) & Most sporadic/ \\
\hline & & www.nads.org & Nondisjunction \\
\hline \multirow[t]{2}{*}{ Hypophosphatemic rickets } & 90 & 1 in $20,000(P)$ & $\mathrm{XL}$ \\
\hline & & www.xlhnetwork.org & \\
\hline \multirow[t]{3}{*}{ Neurofibromatosis (1 and 2) } & 84 & NF1: 1 in $4,000(\mathrm{I})$ & $\mathrm{AD}$ \\
\hline & & NF2: 1 in $40,000(\mathrm{I})$ & \\
\hline & & www.ctf.org & \\
\hline \multirow[t]{2}{*}{ Epidermolysis bullosa } & 66 & 3 in 100,000 (I) 12,000 U.S. (P) & $\mathrm{AD}$ \\
\hline & & www.niams.nih.gov & $\mathrm{AR}$ \\
\hline \multirow[t]{3}{*}{ Chromosome anomalies $^{b}$} & 64 & 1 in 20 known pregnancies; & Sporadic \\
\hline & & 1 in 200 newborns (I) & $\mathrm{AD}$ \\
\hline & & & Continued \\
\hline
\end{tabular}


Table 1

Continued

\begin{tabular}{|c|c|c|c|}
\hline Condition & $\begin{array}{l}\text { No. of } \\
\text { respondents }\end{array}$ & $\begin{array}{c}\text { Incidence }(\mathrm{I}) \text { and/or } \\
\text { population prevalence }(\mathrm{P})\end{array}$ & Inheritance \\
\hline \multirow[t]{2}{*}{ Cyclic vomiting } & \multirow[t]{2}{*}{64} & 1 in 50 children $(\mathrm{P})$ & \multirow[t]{2}{*}{ Complex $^{a}$} \\
\hline & & digestive.niddk.nih.gov & \\
\hline \multirow[t]{2}{*}{ Metachromatic leukodystrophy } & \multirow[t]{2}{*}{62} & 1 in $40,000(\mathrm{P})$ & \multirow[t]{2}{*}{ AR } \\
\hline & & www.nlm.nih.gov & \\
\hline \multirow[t]{2}{*}{ Hypertrophic cardiomyopathy } & \multirow[t]{2}{*}{59} & $1-2$ in $1,000(\mathrm{P})$ & \multirow[t]{2}{*}{$\mathrm{AD}$} \\
\hline & & www.mayoclinic.org & \\
\hline \multirow[t]{2}{*}{ Mitochondrial disorders } & \multirow[t]{2}{*}{53} & 11.5 in $100,000(\mathrm{P})$ & $\mathrm{AD} ; \mathrm{AR}$ \\
\hline & & www.genetests.com & Maternal \\
\hline \multirow[t]{2}{*}{ Cleft lip/palate } & \multirow[t]{2}{*}{48} & 1 in $1,000(\mathrm{I})$ & \multirow[t]{2}{*}{ Complex $^{a}$} \\
\hline & & www.marchofdimes.com & \\
\hline \multirow[t]{2}{*}{ Ehlers Danlos syndrome } & \multirow[t]{2}{*}{48} & 1 in $5,000-10,000(\mathrm{P})$ & $\mathrm{AD}$ \\
\hline & & www.ednf.org & AR \\
\hline
\end{tabular}

$\mathrm{AD}$, autosomal dominant; $\mathrm{AR}$, autosomal recessive; $\mathrm{XL}, \mathrm{X}$-linked.

${ }^{a} \mathrm{~A}$ small subset of complex disorders may be caused by a gene of major effect, but approximately $90 \%$ to $95 \%$ of these cases are caused by both environmental and genetic factors and tend to cluster in families rather than following a clear Mendelian pattern of inheritance.

${ }^{b}$ Includes deletions, duplications, inversions, mosaics, and translocations.



Fig. 1. Percentage of respondents consulting sources of genetics information.

scores (use of multiple sources increased knowledge scores over use of a single source). Although most respondents rated their knowledge between good (3.0) and excellent (4.0), use of advocacy organizations and literature resulted in the greatest increases (a gain of 0.23 in knowledge scores for each of these sources).

\section{Is consultation with genetics-trained provider associated with higher self-assessed knowledge scores than the absence of such consultation?}

Of 5915 respondents, 4604 (78\%) reported seeing a genetics specialist in addition to other providers previously listed; 2236 saw an MD geneticist; 1957 saw a genetic counselor; and 411 saw a nurse specialist in genetics. Those who saw any of the above specialists rated their knowledge of the genetics of the condition in their family significantly higher than those who did not $(3.29$ vs. $3.08 ; P<.001)$. Multivariate analysis indicated that seeing an MD geneticist or a genetic counselor made a significant $(P<.001$ by the Kruskal-Wallis test) independent contribution to respondent knowledge; seeing a nurse did not make a significant independent contribution.

\section{How do patients rank their health care providers' knowledge of the genetics of the condition in the family? How does this compare with rankings of providers' knowledge?}

Table 2 lists the 25 most frequently consulted provider types and ratings for each type's "overall knowledge of the genetics of the condition" in respondents' families. Eighty-five percent of respondents rated their own understanding of the genetics of the condition in the family as good or excellent. Only $2 \%$ of respondents ranked their own knowledge of the genetics of the condition in their family as poor. In contrast, ratings of providers' knowledge as good/excellent ranged between $17.4 \%$ and $62.4 \%$, all of which are significantly $(P<.001$ by the Wilcoxon test $)$ lower than patients' ratings of their own knowledge.

\section{Rating specific skills for the "most important provider" in the provision of care}

Respondents were also asked to indicate the provider type they considered to be most important in the ongoing management of their condition. Primary care physicians filled this role most often (17.2\% indicated family practice and $13.7 \%$ indicated pediatricians). Respondents were asked to rate their most important provider on his/her ability to do the following:

- identify needed services,

- collaborate on developing and monitoring treatment plans,

- understand the medical impact of the condition in the family, and

- understand the psychosocial impact of the condition in the family.

For analysis, primary care providers were grouped and compared with allied health providers and specialist physicians. The primary care means include scores for family 
Table 2

Provider types and knowledge scores

\begin{tabular}{|c|c|c|c|c|}
\hline \multirow[b]{2}{*}{ Provider type } & \multirow[b]{2}{*}{$\begin{array}{l}\text { No. to consult provider } \\
\text { Type } N(\% \text { of } 5915)\end{array}$} & \multicolumn{3}{|c|}{$\begin{array}{l}\text { Respondents' ratings of providers' knowledge of the genetics of the } \\
\text { condition in their family }\end{array}$} \\
\hline & & Poor & Average & Good or excellent \\
\hline Family practice/primary care & $3179(53.7 \%)$ & $39 \%$ & $27 \%$ & $34 \%$ \\
\hline Pediatrician & $2530(42.7 \%)$ & $27 \%$ & $25.3 \%$ & $47 \%$ \\
\hline Cardiologist/electrophysiologist & $2062(35 \%)$ & $22 \%$ & $22 \%$ & $56 \%$ \\
\hline Neurologist & $1885(31.8 \%)$ & $21 \%$ & $23 \%$ & $56 \%$ \\
\hline Ophthalmologist/retinal specialist & $2060(34.8 \%)$ & $22.6 \%$ & $22.4 \%$ & $55 \%$ \\
\hline Pulmonologist & $923(15.6 \%)$ & $20.2 \%$ & $21 \%$ & $58.8 \%$ \\
\hline Endocrinologist & $998(16.9 \%)$ & $23.2 \%$ & $22.6 \%$ & $54.2 \%$ \\
\hline Hematologist/oncologist & $510(8.6 \%)$ & $16.8 \%$ & $25.5 \%$ & $57.7 \%$ \\
\hline Dermatologist & $1172(19.8 \%)$ & $33.2 \%$ & $25.1 \%$ & $41.7 \%$ \\
\hline Gastroenterologist & $1372(23 \%)$ & $29.2 \%$ & $28.3 \%$ & $42.5 \%$ \\
\hline Surgeon & $1620(27.4 \%)$ & $19.6 \%$ & $18 \%$ & $62.4 \%$ \\
\hline Psychiatrist/psychologist & $1102(18.6 \%)$ & $39.3 \%$ & $24.7 \%$ & $36 \%$ \\
\hline Orthopedic specialist & $1382(23 \%)$ & $29.8 \%$ & $23.3 \%$ & $46.9 \%$ \\
\hline Gynecologist & $873(14.7 \%)$ & $39.8 \%$ & $23 \%$ & $37.2 \%$ \\
\hline Nephrologist & $339(5.7 \%)$ & $18.6 \%$ & $19.5 \%$ & $61.9 \%$ \\
\hline Speech-language pathologist & $1546(26 \%)$ & $32.7 \%$ & $25.4 \%$ & $41.9 \%$ \\
\hline Rheumatologist & $341(5.8 \%)$ & $38.6 \%$ & $20.2 \%$ & $41.2 \%$ \\
\hline Nutritionist & $1191(20 \%)$ & $36.8 \%$ & $24.1 \%$ & $39.1 \%$ \\
\hline Otolaryngologist & $869(14.6 \%)$ & $29.5 \%$ & $24.9 \%$ & $45.7 \%$ \\
\hline Physical therapist & $1949(33 \%)$ & $31.4 \%$ & $24.8 \%$ & $43.8 \%$ \\
\hline Urologist & $693(11.7 \%)$ & $34 \%$ & $20.9 \%$ & $45.1 \%$ \\
\hline Occupational therapist & $1726(29 \%)$ & $31.2 \%$ & $26.6 \%$ & $42.2 \%$ \\
\hline Allergist/immunologist & $815(13.8 \%)$ & $52.1 \%$ & $22.5 \%$ & $25.4 \%$ \\
\hline Social worker & $965(16 \%)$ & $42.8 \%$ & $24.7 \%$ & $32.5 \%$ \\
\hline Emergency physician & $1100(18.6 \%)$ & $62 \%$ & $20.6 \%$ & $17.4 \%$ \\
\hline
\end{tabular}

The 25 provider types listed here represent $95 \%$ of all providers identified by respondents in the management of their condition.

practice physicians and pediatricians. The allied health means include scores for physical therapists, occupational therapists, social workers, speech-language pathologists, and psychologists/psychiatrists (psychiatrists were not separated out of this group). The specialist-physician means include cardiologists, oncologists, surgeons, urologists, and so forth (see the list of provider types in Table 2).

Table 3 shows that respondents scored allied health care providers the highest on all four measures, followed by specialist physicians, with primary care providers faring worst (exclusive of the "other" category).

What factors contribute to positive and disappointing experiences with knowledgeable and uninformed providers, respectively?

When asked to explain an experience where they were impressed by a provider's knowledge, 1978 respondents replied. The most prevalent, positive themes expressed are in Table 4 .
When asked to explain an experience when they were disappointed by providers' knowledge, 3828 respondents replied. Table 5 describes the most prevalent, negative themes.

\section{Did self-assessments of knowledge influence respondents' assessments of their providers' knowledge?}

Most provider types received significantly higher knowledge scores from respondents whose self-assessed knowledge was good or excellent than from respondents whose self-assessed knowledge was poor or average $(P<.05-P<.001$ by the Kruskal-Wallis test). The exceptions (nonsignificant differences in provider knowledge scores according to respondents' self-assessed knowledge scores) include audiologists, chaplains, emergency physicians, nephrologists, and otolaryngologists. 
Table 3

Ratings of most important providers' performance

\begin{tabular}{lcccccc}
\hline & $\mathrm{N}$ & $\%$ & $\begin{array}{c}\text { Identify } \\
\text { services }\end{array}$ & $\begin{array}{c}\text { Develop } \\
\text { treatment } \\
\text { plans }\end{array}$ & $\begin{array}{c}\text { Medical } \\
\text { impact }\end{array}$ & $\begin{array}{c}\text { Psychosocial } \\
\text { impact }\end{array}$ \\
\hline $\begin{array}{c}\text { Primary care } \\
\text { physician }\end{array}$ & 1827 & 30.9 & $2.74^{a}$ & $2.63^{a}$ & $2.46^{a}$ & $2.32^{a}$ \\
$\begin{array}{c}\text { Specialist } \\
\text { physician }\end{array}$ & 3164 & 53.5 & 2.90 & 2.93 & 2.75 & $2.46^{b}$ \\
$\begin{array}{c}\text { Allied health } \\
\text { Other }\end{array}$ & 343 & 5.8 & 3.00 & 3.03 & 2.81 & 2.73 \\
Total & 581 & 9.8 & 2.96 & 2.96 & 2.77 & $2.55^{c}$ \\
\hline & 5915 & 100.0 & 2.86 & 2.84 & 2.67 & 2.44 \\
\hline
\end{tabular}

Q1. How would you rate this provider's ability to collaborate with you on ways to identify needed services?

Q2. How would you rate this provider's ability to collaborate with you on ways to develop and monitor treatment plans?

Q3. How would you rate this provider's understanding of the medical impact of this condition on your family?

Q4. How would you rate this provider's understanding of the psychosocial impact of this condition on your family?

Cell entries are means of responses scored poor $=1$, fair $=2$, good $=3$, excellent $=4$

${ }^{a}$ Group mean is significantly $(P<.001)$ lower than all other groups (by Kruskal-Wallis test).

${ }^{b}$ Group mean is significantly $(P<.001)$ lower than the allied health group (by Kruskal-Wallis test).

${ }^{c}$ Group mean is significantly $(P<.05)$ lower than the allied health group (by Kruskal-Wallis test).

All total means are significantly ( $P<.001$ by Wilcoxon test) different from each other except Q1 vs. Q2.

Table 4

Themes that reflect being pleased with providers' knowledge

Qualitative themes that emerged in response to the question:

"Have you ever been pleased by how much a health care provider knew about the condition in your family?"

Knowledgeable, competent, generally pleased

$684 / 1978(35 \%)$

Happy with specialists/specialized institutions

$319 / 1978(16 \%)$

Engages in learning/does research

$223 / 1978(11 \%)$

Sympathetic, listens, explains

$100 / 1978(5 \%)$

Makes appropriate referrals for care/testing

$70 / 1978(4 \%)$

Willing to work with and learn from patient

$66 / 1978(3 \%)$

\section{DISCUSSION}

Although several studies ${ }^{5,8,13,14}$ have investigated the role of genetics in practice, consumers only rarely have been asked to share their perceptions of providers' knowledge of genetics and proficiency in the delivery of genetics-related services. In isolation, the conditions represented in this study affect relatively small numbers of individuals, but in the aggregate, these individuals and families constitute a large population that, increasingly often, deftly negotiates the health care system. These individuals are affected by chronic conditions requiring frequent visits with multiple provider types and therefore have a broader and deeper experience with various health care providers than does the average consumer.
Table 5

Themes that reflect disappointment with providers' knowledge

Qualitative themes that emerged in response to the question:

"Have you ever been disappointed by how little a health care provider knew about the condition in your family?"

Provider lacks interest, willingness, knowledge ${ }^{a}$

$1307 / 3828(34 \%)$

Personally did research and educated provider(s)

$591 / 3828(15 \%)$

Disease rarity limits information for everyone

$269 / 3828(7 \%)$

Information offered was old, conflicting, or incorrect

$190 / 3828(5 \%)$

The diagnosis was missed, incorrect, or delayed

$246 / 3828(4 \%)$

Inappropriate/inadequate care was provided

$198 / 3828(3 \%)$

${ }^{a}$ This category includes the following types of comments: provider lacks interest/knowledge $(n=1099)$, providers did not look for information/research on their own $(n=82)$, provider was nonreceptive to patient-provided information $(n=41)$, non-empathetic or rude $(n=51)$, unwilling to look at differential diagnoses $(n=16)$, and unwilling to admit a lack of knowledge $(n=18)$.

The inclusion of multiple provider types and of conditions with complex and Mendelian causes allowed us to capture a more complete picture of the reach of genetics in health care and to answer nondisease-specific questions about genetic services. As a group, particularly through membership in organizations such as the GA, genetics consumers are increasingly successful in lobbying for national policies such as legislation to prohibit genetic discrimination, in collaborating directly with basic scientists and clinical investigators to identify causative genes and to implement effective therapies, ${ }^{1,15,16}$ and in raising awareness about the role of genes in common, complex diseases that cluster in family histories. Inclusion of this constituency in discussions about the incorporation of genetics into preservice curricula, continuing education, and daily practice is critical to ensure that genetics knowledge is applied appropriately across health care disciplines.

Given their prominence in the care of children and adolescents, it is not surprising that family practitioners and pediatricians were the most frequently consulted and considered "most important" in medical management. It is surprising, however, that $64 \%$ of respondents reported receiving no genetics education from their providers, despite having chronic conditions that pose risks to themselves, their offspring, and other family members. It follows that multiple provider types in multiple clinical settings are overlooking opportunities to provide and discuss genetics-related information with individuals and families.

We are assuming, however, that respondents consult the "most important provider type in the management of their condition" more frequently than other provider types. Therefore, there are more opportunities for these providers to educate their patients about genetics-related issues that arise as their patients and families move through various life stages. One must ask whether providers have the necessary genetics information to seize these opportunities, particularly at the point-of-care, and whether providers view that information as clinically relevant and useful. 
Individuals and families with genetic conditions, however, are not solely reliant on their providers as sources of information. In the absence of genetics information from providers, individuals and families turned to multiple sources. Advocacy organizations and the literature were associated with the largest increases in knowledge scores, suggesting that both sources educate and empower individuals and families with genetic conditions. Because respondents were recruited through advocacy organizations, it also is possible that our sample was highly selective for individuals who would look to such groups for information. Individuals who are members of advocacy organizations get added value for their membership because the organizations often filter, annotate, and refine general information, thereby concentrating its value and enhancing its accessibility.

Seventy-eight percent of respondents reported consulting a genetics professional, which resulted in significantly higher self-assessments of knowledge among respondents to the present survey.

Furthermore, individuals who ranked their own knowledge as good or excellent were, in turn, significantly more generous when scoring the perceived genetics understanding of other types of health care providers. Did respondents who rated their own knowledge more highly somehow direct their interactions with providers toward genetics-oriented questions and care, resulting in higher scores for the providers? Were such respondents simply better able to determine what their providers knew about genetics than were less-well-informed respondents? Were these respondents better educated by informed providers or a priori less tolerant of ill-informed providers? The design of our study did not reveal answers to those questions, but the finding that educated health care consumers (those who rated their own genetics knowledge as good or excellent) in this study gave higher marks to their providers does offer some incentive for providers to pursue genetics education to benefit their patients and the patient-provider relationship.

The provider rankings in Table 2 offer a snapshot of the status of genetics knowledge across disciplines, and there are a few notable trends. First, affected individuals and families with genetic conditions scored specialists higher than generalists, which is logical considering the focused nature of targeted therapies. But the overall distribution of "poor" rankings in Table 2 (minimum $16.8 \%$, maximum 62\%, median $31.2 \%$, average $31.7 \%$ ) indicates that there is much work to be done to incorporate genetics across health care professions in general.

Table 3 , which compares the most frequently consulted providers, highlights the importance of allied health disciplines in primary care and team management. Although allied health professionals were not considered to be the "most important" providers in the management of the condition for the majority of respondents, they scored higher than other providers on specific management skills (i.e., identifying needed services, developing management plans, and understanding the medical and psychosocial impact of the condition in the family), better than primary care and specialist physicians.
The qualitative responses offer insights into the consumers' desire for knowledgeable providers. One attribute that respondents value highly is the provider's willingness to learn and to appreciate the knowledge and practical experience of individuals and families living with chronic conditions. The following quotes, drawn from several hundred, reflect the central importance among respondents of providers' willingness to learn and to be receptive.

1. This is my son's life—not their only patient—but I still want(ed) them to be understanding and knowledgeable about his condition. It is frustrating when you have to be the one to "teach" the doctor.

2. I continually educate my general practitioner. But thankfully she is completely supportive.

3. I normally have to explain to them what my son has, how it was diagnosed, and what symptoms my son presents. Most doctors are afraid of us when they find out and prefer to refer us to another medical professional.

4. I felt I had to do all the research and find other families with the same conditions to talk to. I realize there is little information out there on this condition, but I thought they could have directed me to websites and other support groups instead of having to stumble upon things on my own.

5. Every time I walk into an emergency department it seems I am drawing a sketch of normal and abnormal chromosomes $(\mathrm{t} 11 / 22)$ [a translocation involving chromosomes 11 and 22] and giving a class ... lol ... hey it's how we learn, eh?

6. When my child is sick, it's frustrating to have to explain the syndrome and its implications. I want to focus on my child, not educating the medical staff.

7. We are a military family and move frequently. It is always with great trepidation that we meet our new doctor, always wondering how much we will have to educate the doctor. This is a very delicate situation to be in as you can imagine. It is a relief when we get a doctor who has knowledge of Marfan syndrome or is cooperative about learning.

8. We like our doctor. We don't really expect him to know anything about our syndrome. We teach him.

Education of health care professionals about the genetic contributions to morbidity and mortality is becoming increasingly important as we grow to appreciate the increased empirical risks to relatives when there is a positive family history of complex disease. Similarly, recognition of genetic red flags and Mendelian modes of inheritance is critical for the management of affected individuals and for addressing increased risk to relatives and offspring. Improving providers' knowledge of a large number of rare conditions, however, is unlikely, but improving the inclusion of genetics principles throughout curricula may result in more receptivity among health professionals to their patients and families affected by genetic conditions. 


\section{Limitations}

Several conditions in the final sample were represented by only one individual. In addition, disease names were being added to the online survey drop-down menus several months into data collection, so several hundred respondents may have been excluded inadvertently (surveys that did not specify a condition were excluded from analysis). The online nature of the survey, although accommodating a large number of respondents, also excluded those without Internet access or those with vision impairment. Conversely, ascertainment bias among online survey respondents may have artificially inflated the frequency with which the Internet was cited as a prime resource for genetics information.

The use of "websites" as a source for information did not have a significant independent effect on self-assessed knowledge scores. Although it is tempting to assume that the category "websites" captures sites other than advocacy organization's web portals, we cannot be certain that is the case; respondents may have checked "website" when the website was that of an advocacy organization. The inability to distinguish these sites may have confounded our interpretation of the independent effects of websites on respondents' knowledge scores.

Although a majority of respondents reported receiving no genetics education materials from the provider type they consider most important in the management of their condition, we cannot determine how often respondents may have received genetics education materials before meeting with this provider, for example, at the time of diagnosis from a genetics professional.

In addition, because the knowledge ratings are subjective, we cannot specify what an "average" level of provider knowledge might entail or confirm that respondents truly have a "good" or accurate understanding of the genetics of the condition in their family. The breadth and genetic heterogeneity of conditions among respondents makes establishing a baseline knowledge score for comparison exceptionally daunting. In lieu of doing so, we compared individuals' own knowledge rankings with their assessment of their providers' knowledge. This study, however, involved highly motivated, educated consumers, the majority of whom participate in advocacy organizations and advocacy activities; therefore, any extrapolation of results to the general public is speculative.

One might infer that patients who have a positive feeling about their providers' level of genetics knowledge also have better health outcomes, but we did not measure the correlation between providers' understanding of genetics and patient outcomes.

The measures developed for this study are single items. These may not have the sensitivity of multi-item measures and may not capture all the distinct aspects of the construct being measured. Thus, we might have missed subtle differences. The study's large sample size, however, compensates by providing substantial statistical power to detect small associations. Fu- ture research should consider development of multi-item measures that assess multiple dimensions.

Given these limitations, this study produced a large and varied data set. Next steps include disease-specific and providertype specific analyses. Further study of noncomputer-literate individuals and individuals affected by genetic conditions who are not members of advocacy organizations may be needed to present a more representative picture.

\section{CONCLUSION}

More than $80 \%$ of 5915 respondents reported having between one and four affected family members, having been diagnosed within the last 5 years, and consulting an average of six different provider types (excluding genetics professionals). Despite having chronic genetic conditions that pose risks to themselves, their offspring, and other family members, $64 \%$ of the total study sample reported receiving no genetics education materials from their providers. Therefore, it is reasonable to conclude that multiple provider types in multiple clinical settings are overlooking opportunities to discuss genetics-related information with affected individuals and families over time, particularly as patients transition through various life stages.

These data highlight the importance of allied health providers and demonstrate the need for a team approach to care through communication across disciplines. Allied health providers, in fact, scored higher than primary care and specialist physicians in their ability to collaborate with patients to identify needed services and to develop management plans, and in their understanding of the medical and psychosocial impact of the condition on the family. Yet, the overall distribution of "poor" knowledge rankings among providers indicates that there is much work to be done to incorporate genetics in a clinically meaningful way across disciplines.

In the absence of genetics information from providers, individuals and families turned to multiple sources (including the Internet, advocacy organizations, literature, and classes). In turn, these educated consumers expressed frustration with an apparent lack of receptivity among providers to information about the genetic condition in the family.

Education of health care professionals about the genetic contributions to morbidity and mortality is becoming increasingly important as we grow to appreciate the increased risk to relatives when there is a positive family history of complex disease. Similarly, recognition of genetic red flags and familiarity with Mendelian modes of inheritance is critical for managing affected individuals and addressing increased risk to relatives and offspring. Inclusion of genetics principles in the education of health professionals, and access to clinically relevant genetics content at the point-of-care, may help to improve the care of patients and families affected by genetic conditions.

\section{ACKNOWLEDGMENTS}

This work was supported in part by contract number 230-020007 from the Bureau of Health Professions at the Health Re- 
sources and Services Administration, the Office of Rare Diseases, and by the National Human Genome Research Institute.

We are grateful to Laird Kelly and Daniel Royer, RSi Focal Search, Inc., for construction of the online survey and collection of data, and to Emily Malouf for assistance with the preparation of the article.

\section{References}

1. Terry SF, Boyd CD. Researching the biology of PXE: partnering in the process. Am J Med Genet 2001;106:177-184.

2. Guttmacher AE, Collins FS, Drazen JM, editors. Genomic Medicine: Articles from the New England Journal of Medicine. Baltimore: Johns Hopkins University Press; 2004.

3. Qureshi N, Hapgood R, Armstrong S. Continuous medical education approaches for clinical genetics: a postal survey of general practitioners. J Med Genet 2002;39:e69.

4. Kegley JA. An ethical imperative: genetics education for physicians and patients. Med Law 2003;22:275-283.

5. Hayflick SJ, Eiff MP. Will the learners be learned? Genet Med 2002;4:43-44.

6. Suther S, Goodson P. Barriers to the provision of genetic services by primary care physicians: a systematic review of the literature. Genet Med 2003;5:70-76.
7. Baars MJ, Scherpbier AJ, Schuwirth LW, Lambert W, et al. Deficient knowledge of genetics relevant for daily practice among medical students nearing graduation. Genet Med 2005;7:295-301.

8. Baars MJ, Henneman L, Ten Kate LP. Deficiency of knowledge of genetics and genetic tests among general practitioners, gynecologists, and pediatricians: a global problem. Genet Med 2005;7:605-610.

9. Guttmacher AE, Porteous ME, McInerney JD. Educating health care professionals about genetics and genomics. Nat Rev Genet 2007;8:151-156.

10. Burton H, Kroese M. Genetics. Gene genies. Health Serv J 2003;113:29.

11. Guttmacher AE, Collins FS, Carmona RH. The family history-more important than ever. N Engl J Med 2004;351:2333-2336.

12. National Coalition for Health Professional Education in Genetics. Core Competencies in Genetics Essential for All Health Professionals, 2nd ed. Lutherville, MD: National Coalition for Health Professional Education in Genetics; 2005

13. Korf BR. Genetics in medical practice: the need for a complete makeover. Genet Med 2005; 7:293-294.

14. Finn CT, Wilcox MA, Korf BR, Blacker D, et al. Psychiatric genetics: a survey of psychiatrists' knowledge, attitudes, opinions, and practice patterns. JClin Psychiatry 2005;66:821-830.

15. Terry SF, Davidson ME. Empowering the public to be informed consumers of genetic technologies and services. Community Genet 2000;3:148-150.

16. Terry SF. Learning genetics. Health Aff (Millwood) 2003;5:166-171. 